TITLE:

\title{
Quantification of seismic damage in steel beam-column connection using PVDF strain sensors and model-updating technique
}

\section{AUTHOR(S):}

Suzuki, Akiko; Kurata, Masahiro; Li, Xiaohua;

Minegishi, Kaede; Tang, Zhenyun; Burton, Andrew

\section{CITATION:}

Suzuki, Akiko ... [et al]. Quantification of seismic damage in steel beam-column connection using PVDF strain sensors and model-updating technique. Sensors and Smart Structures Technologies for Civil, Mechanical, and Aerospace Systems 20152015

\section{ISSUE DATE:}

2015-03

URL:

http://hdl.handle.net/2433/265312

\section{RIGHT:}

Copyright 2015 Society of Photo-Optical Instrumentation Engineers (SPIE). One print or electronic copy may be made for personal use only. Systematic reproduction and distribution, duplication of any material in this publication for a fee or for commercial purposes, and modification of the contents of the publication are prohibited;; Akiko Suzuki, Masahiro Kurata, Xiaohua Li, Kaede Minegishi, Zhenyun Tang, and Andrew Burton "Quantification of seismic damage in steel beam-column connection using PVDF strain sensors and model-updating technique". Proc. SPIE 9435, Sensors and Smart Structures Technologies for Civil, Mechanical, and Aerospace Systems 2015, 94352 E (27 March 2015); https://doi.org/10.1117/12.2085300 


\title{
Quantification of seismic damage in steel beam-column connection using PVDF strain sensors and model-updating technique
}

\author{
Akiko Suzuki $^{a}$, Masahiro Kurata*a, Li Xiaohua ${ }^{\mathrm{a}}$ \\ Kaede Minegishi $^{\mathrm{a}}$, Tang Zhenyun ${ }^{\mathrm{b}}$, Andrew Burton ${ }^{\mathrm{c}}$ \\ ${ }^{a}$ Disaster Prevention Research Institute, Kyoto University, Gokasho, Uji, Kyoto 611-0011, JAPAN; \\ ${ }^{b}$ College of Architecture and Civil Eng., Beijing University of Technology, Beijing 100124, CHINA; \\ ${ }^{c}$ Dept. of Civil and Environ. Eng., University of Michigan, Ann Arbor, MI 48109-2125, USA
}

\begin{abstract}
This paper presents an experimental verification of a method of evaluating local damage in steel beam-column connections using modal vibratory characteristics under ambient vibrations. First, a unique testing method is proposed to provide a vibration-test environment which enables measurements of modal vibration characteristics of steel beamcolumn connection as damage proceeds. In the testing method, a specimen of structural component is installed in a resonance frame that supports large fictitious mass and the resonance frequency of the entire system is set as the natural frequency of a mid-rise steel building. The specimen is damaged quasi-statically, and resonance vibration tests are conducted with a modal shaker. The proposed method enables evaluation of realistic damage in structural components without constructing a large specimen of an entire structural system. The transition of the neutral axis and the reduction of the root mean square (RMS) of dynamic strain response are tracked in order to quantify damage in floor slabs and steel beams, respectively. Two specimens of steel beam-column connection with or without floor slab were tested to investigate sensitivity of the damage-related features to loss of floor composite action and fractures in steel beams. In the end, by updating numerical models of the specimens using the identified damage-related features, seismic capacities of damaged specimens were estimated.
\end{abstract}

Keywords: Damage quantification; Steel beam-column connection; Dynamic strain; Model updating; Wireless sensing

\section{INTRODUCTION}

Post-earthquake damage assessments of buildings are particularly essential to support decision-making in evacuation or re-occupancy policy for future earthquakes. In case of an emergency situation, stakeholders and occupants of buildings face difficulties due to a lack of information on structural status (i.e., damage level or residual performance). At the present moment, however, damage extent of buildings is visually assessed by registered inspectors, which requires considerable labors and time. Especially for steel buildings, severe damage such as fracture at connections are hardly identifiable by visual inspection in many cases since almost all steel members are covered by fire-proofing and architectural finishing. In the 2011 Tohoku earthquake in Japan, for example, more than 95,000 earthquake-affected buildings were suspected for safety and required over a three-month period inspection. It was also reported that inspection was delayed or re-conducted due to the damaging aftershocks in some cases [1].

In response to this situation, Structural Health Monitoring (SHM), which utilizes information from state of the art sensing systems deployed permanently to buildings, attracts a great attention as post-earthquake diagnosis tools. In general, SHM systems in building applications can be classified in two, global and local monitoring, depending on their objectives. Global monitoring senses overall behavior of structures (e.g. floor accelerations or story drifts), from which the reduction of natural frequencies, story stiffness or hysteresis properties are evaluated [2], [3]. Local monitoring senses responses at individual members (e.g., beam accelerations or strains), from which local damages at structural members are identified [4], [5]. This is beneficial for the purpose to identify detailed damage information and to estimate structural residual capacity by updating damaged structural elements with an analyzed model one by one [6]-[8]. For

Sensors and Smart Structures Technologies for Civil, Mechanical, and Aerospace Systems 2015,

edited by Jerome P. Lynch, Kon-Well Wang, Hoon Sohn, Proc. of SPIE Vol. 9435, 94352E

(C) 2015 SPIE · CCC code: $0277-786 X / 15 / \$ 18 \cdot$ doi: $10.1117 / 12.2085300$ 
steel buildings, local monitoring may plays an important role because damage concentrate at member ends and the overall responses remain similar until damage progress to very severe (e.g., large fractures at many locations). The other challenge in steel buildings is a presence of composite actions mainly by floor slabs. A past research on local damage by the authors on influence of floor slab to the lateral stiffness or vibratory characteristics of beam-column connection [9] indicated that the influence was considerable enough to be equivalent to bottom flange fracture in some cases, and global characteristics monitoring, such as identifications of natural frequency and mode shape, may not be sufficient to distinguish these damages.

This research first presents a unique testing method which provides a vibration-test environment which enables measurements of modal vibration characteristics of steel beam-column connection as damage proceeds. In the test, beam-column connection specimens of a mid-rise steel building with and without floor slab were damaged and their modal vibration characteristics were monitored using a wireless dynamic strain monitoring system [4]. In particular, the transition of beam neutral axes caused by floor slab damages and the reduction of dynamic strain responses caused by beam damages were investigated. Moreover, an analysis model of the specimen was built and updated using dynamic strain responses. This model-updating was particularly interested as it provided estimates on the residual seismic capacities of the specimens in terms of the quantities familiar to structural engineer (i.e., stiffness and strength).

\section{SUBSTRUCTURE RESONANCE TEST}

\subsection{Test system for damage monitoring}

The test system shown in Figure 1 was developed to damage a building substructure such as beam-column connections with quasi-static cyclic loading and to investigate its inner-force distribution when subject to the natural mode components of ambient vibrations. In order to excite substructure responses under the natural mode vibration of the building where the substructure was taken from, the substructure was connected with additional mass and vibrated as a simple SDOF system [Figure 1(a)].

Figure 1(b) shows the test system. A beam-column connection specimen was connected to a pin-frame which supported the additional mass made of steel plates. For the quarter-scaled specimens explained in the following section, the natural frequency of the system was adjusted to $1.7 \mathrm{~Hz}$. In full scale, this frequency was equivalent to $0.85 \mathrm{~Hz}$, a typical natural frequency of mid-rise buildings. Cyclic loading was applied in the lateral direction by controlling the drift angle of the specimen with a loading system consisted of a hydraulic jack and a pump, and a controller. The specimen was unloaded to the initial state when notable damage occurred, and then the jack was detached temporarily. Resonance test was conducted by inputting white noise with $0.5 \mathrm{~Hz}-40 \mathrm{~Hz}$ frequency band to the pin-frame using a modal shaker (APS 113, APS Dynamics) firmly attached to the additional mass. The sampling frequency and measurement duration were $100 \mathrm{~Hz}$ and 150 second, respectively.

In summary, the test proceeded as follows: i) seismic damages were induced to the substructure specimen by applying lateral force using the quasi-static loading system; ii) at every notable damage stage, the loading system was detached temporarily and the resonance at natural vibration mode was excited using a modal shaker.

\subsection{Test specimens}

There were two types of specimens, a beam-column connection with or without floor slab. The dimensions of a specimen with floor slab are shown in Figure 2(a). The specimen had a story height of 1,000 $\mathrm{mm}$ and a beam span of $2,000 \mathrm{~mm}$, which corresponds approximately to a quarter size of original scale. The column has a hollow steel section $(\square-100 \times 100 \times 9)$ and was made of SM490 steel with the nominal yield strength of $325 \mathrm{MPa}$. The beams were I-shapes $(\mathrm{H}-100 \times 60 \times 6 \times 8)$ made of SS400 steel with the nominal strength of $235 \mathrm{MPa}$. In the figure, X1 and X2 denote the left beam-ends and the right beam-ends respectively. Beam and column were welded with CJP groove welding using thoughtype diaphragms. The floor slab $(2000 \mathrm{~mm} \times 500 \mathrm{~mm} \times 120 \mathrm{~mm})$ with reinforcing meshes was casted and connected with the steel beam using hexagonal bolts (diameter $6 \mathrm{~mm}$, height $20 \mathrm{~mm}$, as a substitute of the headed stud) welded to the top flanges with an interval at $40 \mathrm{~mm}$. The additional mass supported by the pin-frame was $4,000 \mathrm{~kg}$. 


\subsection{Sensing system}

Dynamic strain sensors and acceleration sensors were used to measure the vibration responses of the specimens. The data were collected though wireless communication modules NARADA (Civionics, LLC). Figure 2(b) shows the layout of the sensors. The dynamic strain sensor was a PVDF (Poly Vinylidene Di Fluoride) film (DT1-028K, Tokyo sensor). The PVDF film outputs approximately $12 \mathrm{mV}$ per 1 micro strain and covers the broad range of frequency of $0.001 \mathrm{~Hz}$ to a few MHz. Dynamic strain responses of the beams were measured at three sections (P1 to P3). At the beam sections, the axial strains induced by bending moments were measured at the top and bottom flanges. At the column section, the axial strains were measured at two facing column surfaces in the direction of loading. To identify the mode shape of the specimen, six MEMS accelerometers (Silicon design, 2012-002) were placed on the top flanges of the beams. The accelerometer had the frequency range of DC to $300 \mathrm{~Hz}$ and the output range of $\pm 2 \mathrm{~g}$. The initial vibratory characteristics of the specimen with the floor slab were examined at undamaged state. The RMS (root mean square) of the acceleration response at the column top (AC7) was $0.024 \mathrm{~m} / \mathrm{s}^{2}$. The first mode shape of the beams was point symmetry about the joint as those observed in beams in building deformed laterally with story drifts. A typical RMS value of beam strain responses was $6.4 \mu \varepsilon$. The identified resonance frequency was $1.84 \mathrm{~Hz}$, which was close enough to the expected value in the design, $1.7 \mathrm{~Hz}$. At this resonance frequency, the dynamic strain responses had very low noise levels and high $\mathrm{S} / \mathrm{N}$ ratios.

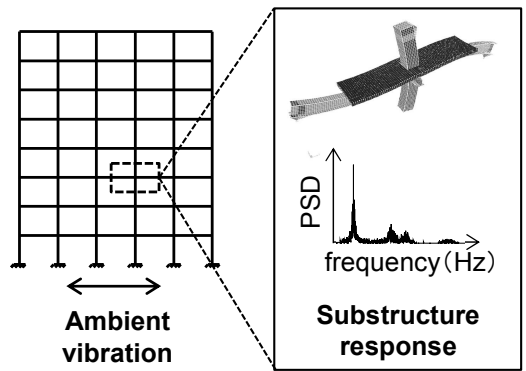

(a)

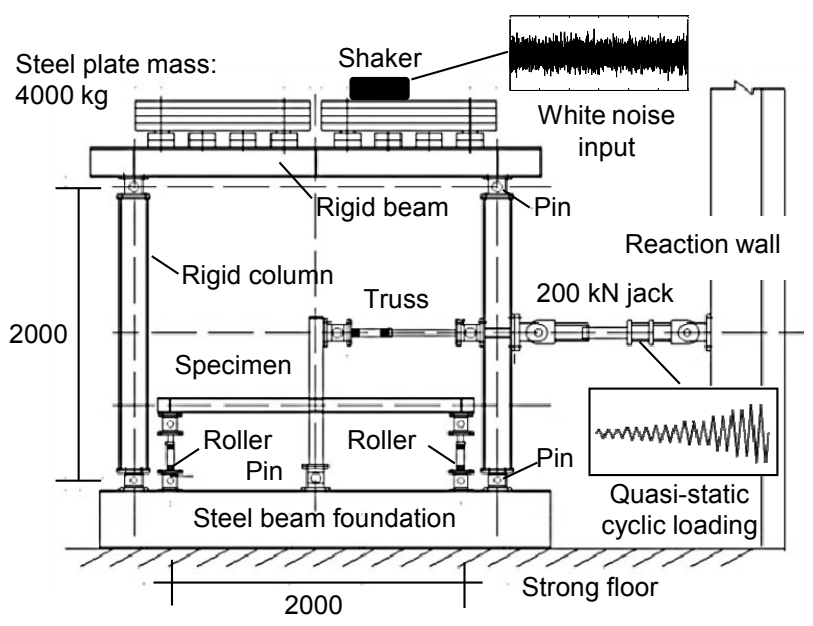

(b)

Figure 1. Substructure resonance test: (a) concept of system; (b) test setup.

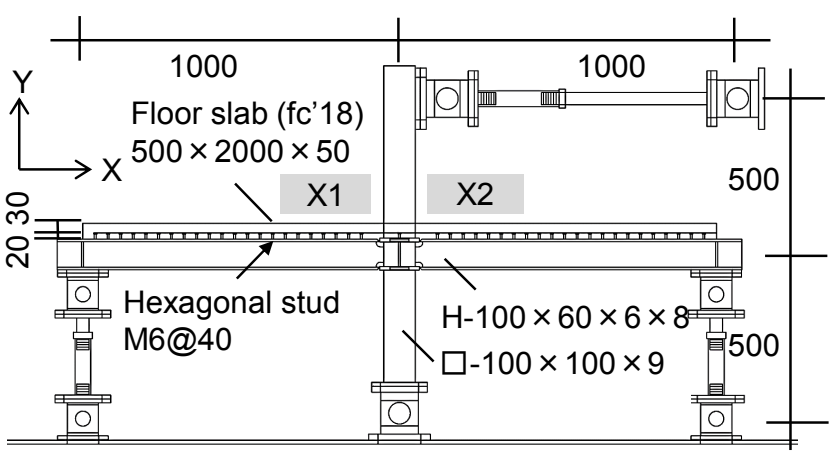

(a)

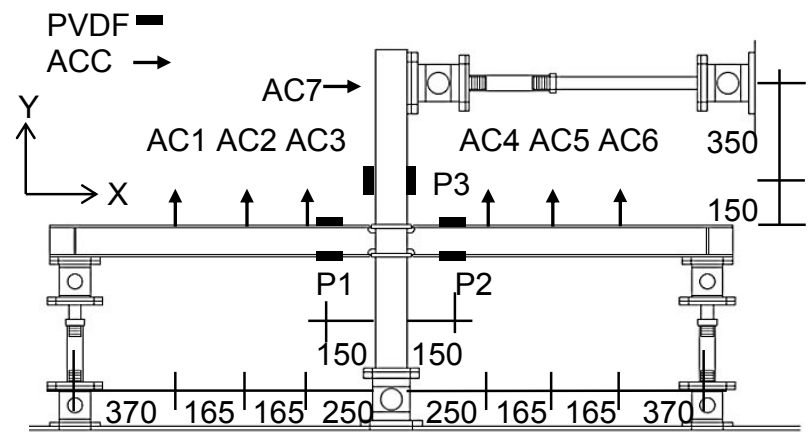

(b)

Figure 2.Specimen and sensing system: (a) dimensions; (b) sensor layout. 


\section{LOADING PROTOCOL AND DAMAGE CASES}

The loading was continued until the specimens significantly lost lateral load-resisting capacities. When notable damage progressed in the specimens, the loading protocol was paused and Figure 3 and Table 1 show the overall behavior and defined damage cases for each specimen.

\subsection{Specimen without floor slab}

During the cyclic loading, two repetitive loading cycles were applied at respective drift angles of $0.5 \%, 1.0 \%, 2.0 \%$, $3.0 \%, 4.0 \%, 5.0 \%$, and $6.0 \%$. The drift angle was computed as the lateral displacement of the column top over the column height (i.e. story height). Then, loading was repeated at the drift angle of $8.0 \%$ until fracture occurred at the ends of the both beams. The specimen yielded at the drift angle of $1.5 \%$. A ductile crack initiated from the toe of the weld access hole at the beam end X1 at the first cycle of $8 \%$ drift angle (ductility $\mu=5.3$ ). The crack propagated and formed a fracture of the two third of the bottom flange during the second cycle of the same drift angle. At the third cycle, the fracture progressed to the entire bottom flange. At the fifth cycle, facture reached from one third of the web to the entire web. Finally, the test ended with the complete loss of the bending moment resisting capacity at one beam-end X1. In total, seven damage cases were defined: A1 at undamaged condition; A2 after initial yielding; A3 and A4 after reaching plastic strength at the beam ends; A5 at the fracture of two third of the bottom flange at X1; A6 at fracture of the entire flange and one third of the web at X1; A7 at the fracture of the entire flanges and webs at X1. No fracture was observed at $\mathrm{X} 2$.

\subsection{Specimen with floor slab}

A loading protocol similar to that for the specimen without floor slab was adopted. For two repetitive loading cycles, a drift angle of $0.25 \%$ was added. To collapse, cyclic loading was repeated at the drift angle of $6 \%$. At small deformation, small cracks initiated when the floor slab was subject to compressive force generated by the contact to the column surface. At the drift angle of $0.50 \%$, beam bending initiated cracks in both longitudinal and transverse directions of the beam. As loading amplitude increased, the cracks spread large and deep. After the drift angle of $3.0 \%$, there was no notable crack growth in the floor slab; the number of small cracks increased around the column. The steel beam yielded at the drift angle of $1.84 \%$, and the ductile crack initiated at the toe of the weld access hole during the second cycle of $5.0 \%$ drift $(\mu=3.2)$. The four fifths of the bottom flange at the beam-end X1 fractured during the first cycle of $6.0 \%$ drift $(\mu=3.8)$. At the other beam-end X2, the ductile crack initiated from the toe of the weld access hole at the fifth cycle, and then completely fractured at the same cycle. The loading ended when the half of the web of the beam end X2 fractured at the sixth cycle. The ten damage cases were defined: B1 at undamaged condition; B2 to B7 for the slab damage; B8 at the fracture of the bottom flange at $\mathrm{X} 1 ; \mathrm{B} 9$ at the fracture of the entire flange and web in negative and the bottom flange at $\mathrm{X} 2 ; \mathrm{B} 10$ at the fracture of the half of the web at X2.
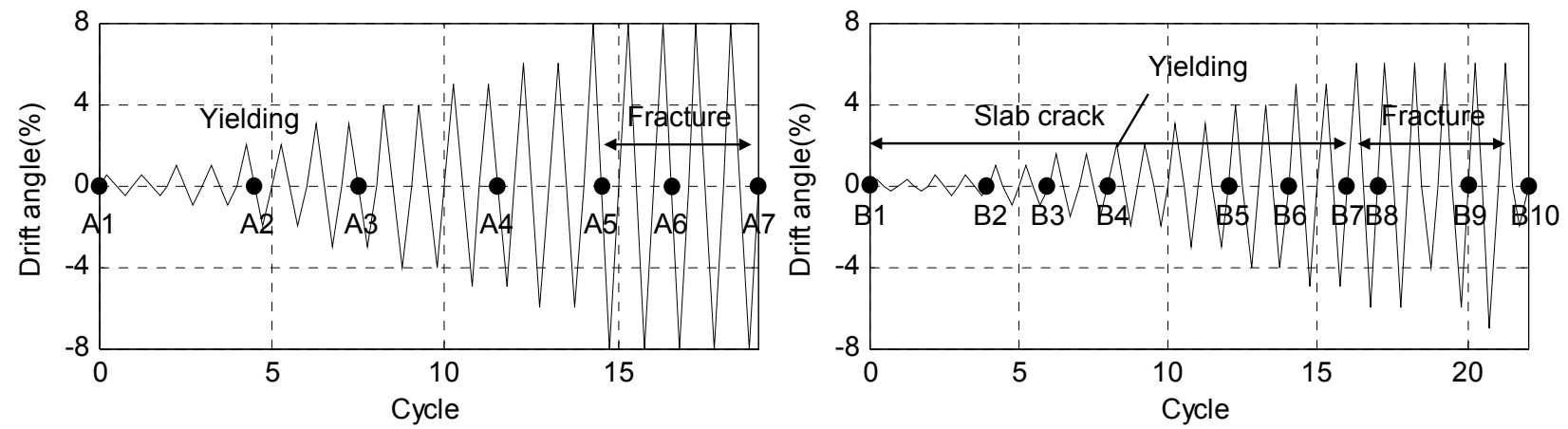

Figure 3. Damage progress: (a) specimen without floor slab; (b) specimen with floor slab. 
Table 1 Damage case definition.

\begin{tabular}{|c|c|c|c|c|c|c|}
\hline $\begin{array}{c}\text { Case } \\
\text { (No slab) }\end{array}$ & A1 & A2 & A3, A4 & A5（X1） & A6 (X1) & A7 (X1) \\
\hline $\begin{array}{c}\text { Damage } \\
\text { extent }\end{array}$ & $\sqrt{5}$ & & & & $\square$ & \\
\hline Drift angle & $0 \%$ & $2 \%$ & $3-5 \%$ & \multicolumn{3}{|c|}{$8 \%$} \\
\hline Ductility & 0 & 1.3 & $2.0-3.3$ & \multicolumn{3}{|c|}{5.3} \\
\hline $\begin{array}{c}\text { Case } \\
\text { (With slab) }\end{array}$ & B1 & B2-B7 & B8 (X1) & \multicolumn{2}{|c|}{ B9 $(\mathrm{X} 1, \mathrm{X2})$} & $\mathrm{B} 10(\mathrm{X} 1, \mathrm{X} 2)$ \\
\hline $\begin{array}{c}\text { Damage } \\
\text { extent }\end{array}$ & & 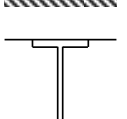 & & & & \\
\hline Drift angle & $0 \%$ & $0.5-5 \%$ & \multicolumn{4}{|c|}{$6 \%$} \\
\hline Ductility & 0 & $0.3-3.2$ & & & & \\
\hline
\end{tabular}

\section{DAMAGE SENSITIVE FEATURES}

In this chapter, damage sensitive features for concrete cracks and steel beam fracture were introduced. The transition of neutral axes and the reduction of dynamic strain responses were used for evaluating the loss of the composite action for floor slab cracks and fractures on steel beams, respectively. Then, their sensitiveness to damages was examined with the results of the resonance vibration tests.

\subsection{Detecting cracks of slab: Transition of neutral axis}

According to the research by Sigurdardottir et al [10], the position of neutral axes in composite beam section can be evaluated with a sufficient accuracy using strain measurements of steel beams. Thus, the transitions of neutral axis in composite beam section were examined for static loading tests and resonance vibration tests. The dynamic neutral axis was defined as the RMS ratio of dynamic strain responses at the top and the bottom flanges $\left(\dot{\varepsilon}_{\text {top }}\right.$ and $\left.\dot{\varepsilon}_{\text {bottom }}\right)$ and the beam height $H$ as follows:

$$
N A=\frac{\left(\varepsilon_{\text {top }}^{i}\right)_{R M S}}{\left(\varepsilon_{\text {botom }}^{i}\right)_{R M S}+\left(\varepsilon_{\text {top }}^{i}\right)_{R M S}} \cdot H
$$

The static neutral axes were estimated as the ratio of static strains of the top and bottom flanges at the location P1 and P2, separately for cases where concrete slab was in compression and in tension. The dynamic neutral axis was assumed to be the average of the two static neutral axes as the concrete slab subject to compression and tension repeatedly under ambient vibrations. The dynamic neutral axes shifted closer to the centroid of the steel beam section as the composite action decreased with cracks.

Figure 4 shows the transitions of the dynamic neutral axis and the average of the static neutral axes both measured at P1. The coordinate corresponds to the location in the beam section with zero corresponding to the centroid of the beam section and positive and negative 0.5 corresponding to the top and bottom flanges. The results show that even small cracks in concrete at Case B2 influenced the dynamic neutral axis and moved it down by $72 \%$. After Case B2, it gradually moved closer to the centroid as damage in the floor slab proceeded. It should be noted that the transition of the dynamic neutral axis and the averaged static neutral axis were similar except at the initial state where the floor slab right after fabrication also contributed in tension. The loss of composite action significantly correlated with the transition of the dynamic neutral axis. 


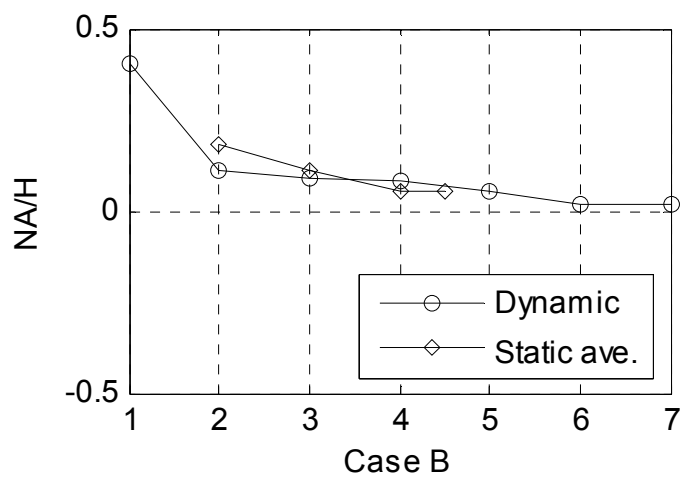

Figure 4. Transition of neutral axis.

\subsection{Detecting fracture of beam: Change of strain distribution}

Ambient vibrations monitored at lateral-load-resisting members in buildings include components of the natural vibration modes of the buildings. When a natural mode shape remains similar and building behaves linearly, the bending moment distribution in the building at the natural mode is uniquely determined by the stiffness distribution of the lateralload-resisting members. In addition, the bending-moment ratios between different lateral-load-resisting members are independent to the characteristics of input ground motions since the ratios remain same under equivalent modal static loads. Kurata et al evaluated the damage extent of steel beams by evaluating the local changes in bending moment distribution using dynamic strain responses [4], [5]. In the method, damage index $S D$ based on changes in dynamic strain distributions is defined by Eq. (2).

$$
S D=\frac{R_{d}^{i}-R^{i}}{R^{i}} \cdot 100(\%), \quad R^{i}=\frac{\left(\varepsilon_{\text {beam }}^{i}\right)_{R M S}}{\left(\varepsilon_{\text {reference }}^{i}\right)_{R M S}}
$$

where $R^{i}$ is the ratio of dynamic strains at a monitored beam, $\dot{\varepsilon}_{\text {beam }}$, and any reference points, $\dot{\varepsilon}_{\text {reference. }}$. The measurement point at the monitored beam shall be reasonably away from damage location to avoid influence by the local strain redistribution such as fracture ( $\mathrm{Li}$ et al proposed the appropriate distance as around 2.0 times the depth of the steel beam section in [5]). The $S D$ of the damaged beam is expressed as the reduction of dynamic strain ratio at any damaged states to undamaged state. In this resonance vibration test using the substructure specimen, the damage index $S D^{*}$ for beamcolumn connection was slightly modified as:

$$
S D^{*}=\frac{R_{d}^{i}-R^{i}}{R^{i}} \cdot 100(\%), \quad R^{i}=\frac{\left(\varepsilon_{\text {beam }}^{i}\right)_{R M S}}{\left(\varepsilon_{\text {reference }}^{i}\right)_{R M S}} .
$$

where dynamic strain responses of an intact column multiplied by the ratio of lateral stiffness (the ratio of the bending moment) at a damaged state to that at the undamaged was used as the reference. That was because all the members in the specimen were influenced by the local change in the bending moment distribution.

For the two specimens with or without floor slab, the dynamic strain reduction was computed by the Eq. (3), and the changes induced by local damages were tracked. Figure 5(a) shows the dynamic strain responses measured at the bottom flanges for the specimen without floor slab at the sensor locations P1 and P2. Note that dynamic strains of the beams were affected by steel yielding. The first significant reduction was observed in P1 at Case A5 with the two of third bottom flange fracture. At the ultimate stage, the strain responses decreased by more than $99 \%$ at Case A7. The dynamic strain measured at P2 decreased by $25 \%$ after Case A6 even no significant fracture was observed. That was probably because of the extra reduction of the beam stiffness induced by the out-of-plain deformation of the pin-supported beamends at very large deformation.

Figure 5(b) shows the dynamic strain responses measured at the bottom flanges of the specimen with floor slab. Before fracture initiated, the dynamic strain at P1 remained similar until Case 7 and decreased by $25 \%$ with fracture of the bottom flange at Case B8. However, the responses at P2 increased at most by $31 \%$ before fracture initiated mostly due to the loss of composite action. This behavior was different from the responses observed at P1. Then, the responses 
decreased by $29 \%$ at Case B8 when the bottom flange at P1 fractured, and decreased by $98 \%$ at Case B9 when the bottom flange and web completely fractured. At Case B10, however, the dynamic strain increased although any notable damage progressed. That was likely because severe damage in the other side (X2) somewhat influenced the strain response at $\mathrm{P} 1$.

The test results indicated that dynamic strain responses were insensitive to yielding but significantly sensitive to fractures at beam ends. In some cases, however, they were also affected by out-of-plane deformation, loss of composite action and severe damage in neighboring beam-ends. These influences need further investigations in future.

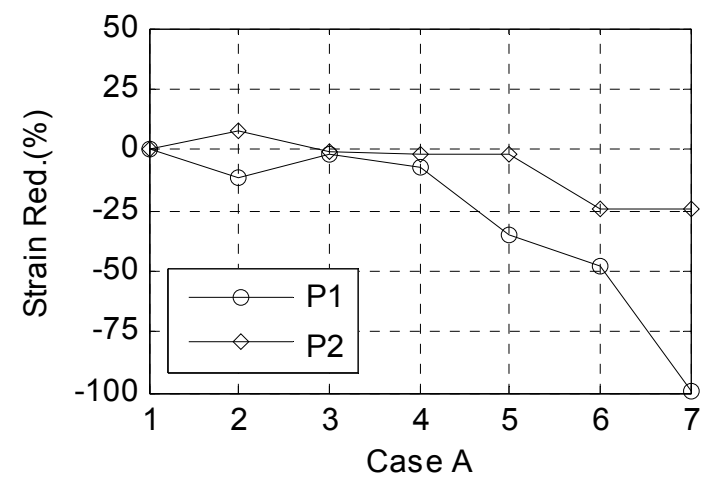

(a)

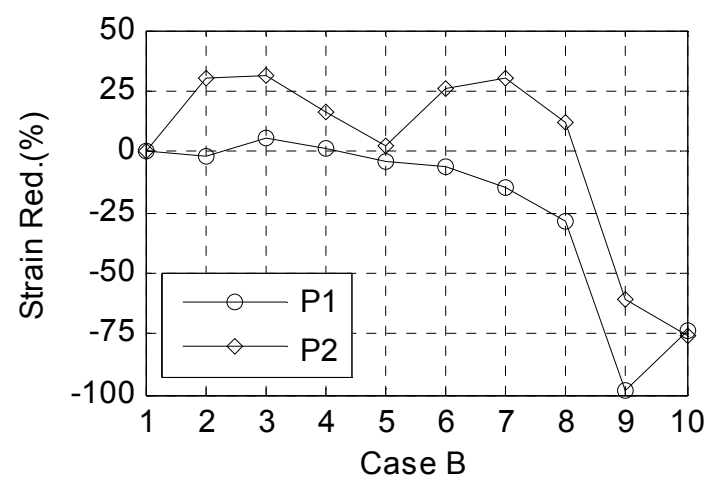

(b)

Figure 5 Changes in dynamic strain distribution: (a) specimen without floor slab; (b) specimen with floor slab.

\section{SEISMIC CAPACITIES EVALUATION WITH DAMAGE-RELATED FEATURES}

Based on the study of damage indices for the beam-column connection specimens, a model-updating strategy to evaluate seismic capacities of damaged beam-column connections is explored. In the strategy, analysis models of monitored beam-column connection are built and updated using dynamic strain responses.

\subsection{Analysis model}

The analysis models of the beam-column connection specimens were built using a general-purpose structural analysis software, OpenSees [11]. The beams were divided into ten elements in axial direction and the columns were modelled with single element. In the model, the beam and column elements were modeled using material nonlinear fiber sections. The section of the steel beam had ten and four fibers along the height and thickness directions of the web, and one and four fibers along the width and thickness directions of the flange. The panel zone was rigid. The beam ends were rollersupported and the column base was pin-supported. To account for stiffness reduction associated with fracture, rotational spring elements were inserted between the beams and the rigid panel. For the specimen with floor slab, the slab thickness was same as the height of the hexagonal bolts, $30 \mathrm{~mm}$, assuming that the cover concrete had no contribution to stiffness and strength: the details of the floor slab model is explained in the next section. The stress-strain relationship of steel was bilinear with Young's modulus $E_{\mathrm{s}}$ of $205 \mathrm{GPa}$, a yield stress $\sigma_{y}$ of $330 \mathrm{MPa}$, and a strain hardening ratio $1.0 \%$. Popovics model [12] was used to the floor slab section with an initial elastic modulus of concrete, $E_{c}$, as $17.4 \mathrm{GPa}$, and a compressive strength of $13.2 \mathrm{MPa}$ ( $85 \%$ of the 28 days strength).

\subsubsection{Damage model for floor slab}

Figure 6 illustrates a damage model for the floor slab. The floor slab section is divided into five layers along the thickness direction and ten elements along the longitudinal direction. The rule for updating the floor slab is as follows. At each element, layers are erased when the applied bending moment at the middle of the slab element reaches predefined values in negative bending. The initial threshold is set as $20 \%$ of the full-plastic strength of the steel beam, $M_{p}$, when the concrete at the outmost layer approximately reaches the tensile strength. As shown in the figure, all five layers are erased in slab elements when subject to $M_{p}$. 
The analysis model is updated until the neutral axis height in the analysis model and the specimen identified by the dynamic strain responses become close each other. Thus, the objective function $J E I_{\text {eff }}$ for updating the analysis model is defined as follows:

$$
J_{-} E I_{e f f}=\frac{N A^{S}-N A^{T}}{N A^{T}}<a .
$$

where $E I_{\text {eff }}$ is an effective bending stiffness of the damaged composite beam; $N A^{\mathrm{T}}$ is the neutral axis height measured in the experiment, and $N A^{\mathrm{S}}$ is the neutral axis height computed in the analysis model. The damage extent in floor slab is estimated by identifying the height of the neutral axis with error less than $a$.

\subsubsection{Beam fracture model}

A fracture near the joint affects the beam stiffness through two factors: (1) the moment inertia of the fractured section and (2) the region neighboring to the fractured section with a reduced fixity [13]. In this paper, the region affected by fracture is accounted by determining an equivalent fracture length, $L_{e f f}$, as shown in Figure 7 . Following the analytical study on crack modelling by Sinha et al [14], the equivalent fracture length is defined as 0.75 times the beam depth. Then, the beam element with the equivalent fracture length is replaced with a damage spring model.

The rotational stiffness of the spring $k_{c}$ is updated by using dynamic strains at beam bottom flanges. Given the measured dynamic strain $S D^{\mathrm{T}}$ and the analyzed $S D^{\mathrm{S}}$, and threshold $a(1 \%)$, the objective function $J k_{c}$ for model updating is defined as

$$
J_{-} k_{c}=\frac{S D^{S}-S D^{T}}{S D^{T}}<a .
$$

\subsection{Residual seismic performance}

The residual capacities of the beam-column specimens were evaluated using the proposed model-updating strategy. For illustration purpose, this paper only shows the model-updating results for the floor slab damage in the specimen with floor slab and the beam fracture in the specimen without floor slab.

\subsubsection{Floor slab damage}

Figure 8 shows the residual seismic capacities of the specimen with floor slab estimated by the model-updating and these identified by the quasi-static loading test. The damage cases considered were Case B2 to Case B7 where the loss of composition action proceeded. The seismic capacities were evaluated in term of the lateral stiffness and the strength of the beam-column connection specimen. In the analysis, these characteristics were estimated by monotonic pushover and the test, they were identified from the force-displacement relationship. For all damage cases, the updated model had the residual stiffness very similar to the measured with the error of $10 \%$. The strength of the updated model also had very good match with the test result with the maximum error of $21 \%$ at Case B3. The both results showed a strong potential of the proposed mode-updating strategy for slab damage while a further investigation is desirable to improve accuracy.

\subsubsection{Beam fracture}

Figure 9 shows the results of the model updating for the specimen without floor slab. The fracture progressed from Case A5 to Case A7 were considered. The residual seismic capacities were evaluated in term of the lateral stiffness and strength of the specimen, and the rotational stiffness of the damage spring. Note that quasi-static loading was not conducted after Case A7 for a safety reason in the test and thus, at Case A7, the residual stiffness was estimated as unloading stiffness and the strength was not obtained. The moment of inertia at the fractured section was estimated by reconverting the spring model to the equivalent fracture model and was compared with that estimated from visual observation. The errors in the estimated values to the measured were at most $20 \%$ for any characteristics. The modelupdating successfully tracked the reduction of the seismic capacities for the specimen without floor slab. In this study, the number of damage cases was not enough to fully discuss the source of error and further researches are needed. 


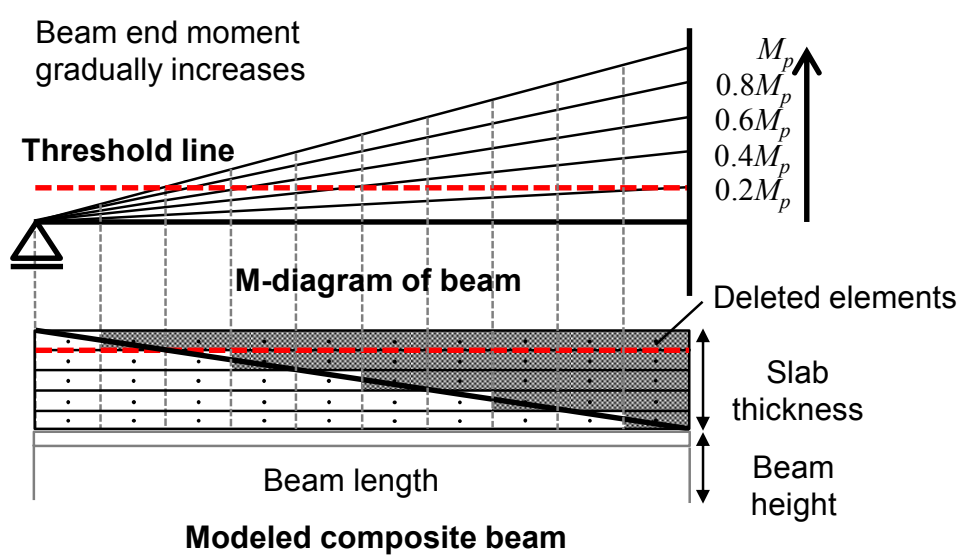

Figure 6 Loss of composite action for slab section.

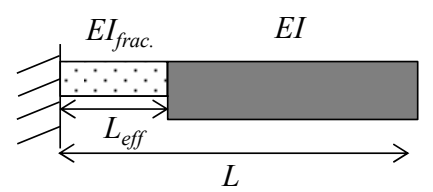

(a)

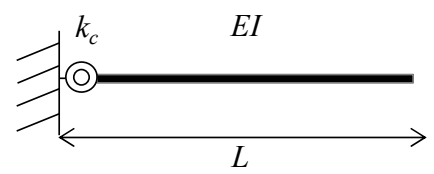

(b)

Figure 7 Beam fracture model: (a) Equivalent length model; (b) Spring model.

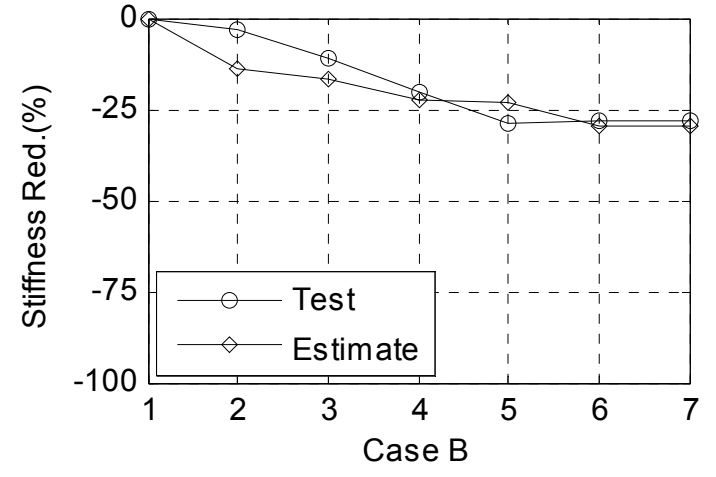

(a)

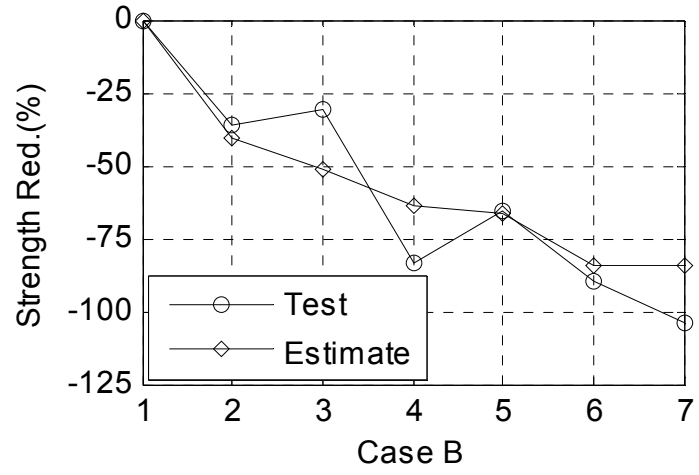

(b)

Figure 8 Model-updating results for specimen with floor slab: (a) Residual stiffness of composite beam; (b) Loss of composite action due to floor slab. 


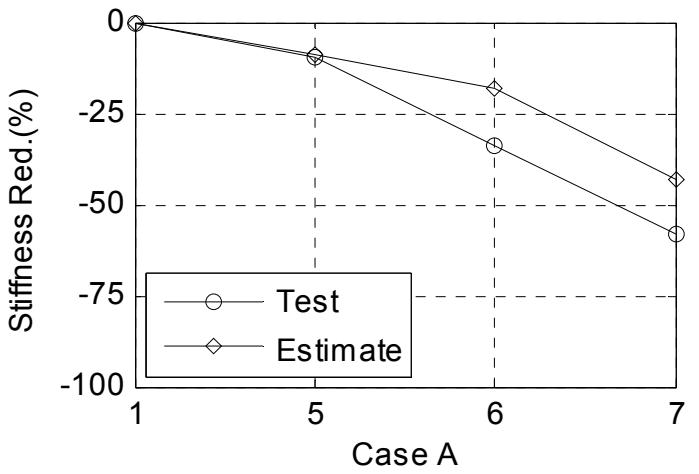

(a)

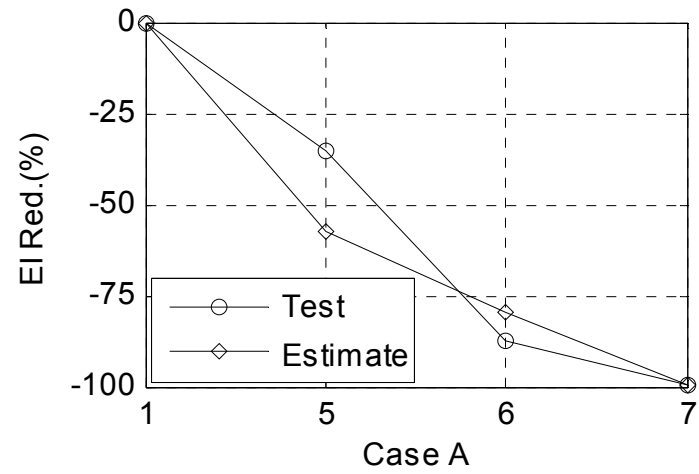

(b)

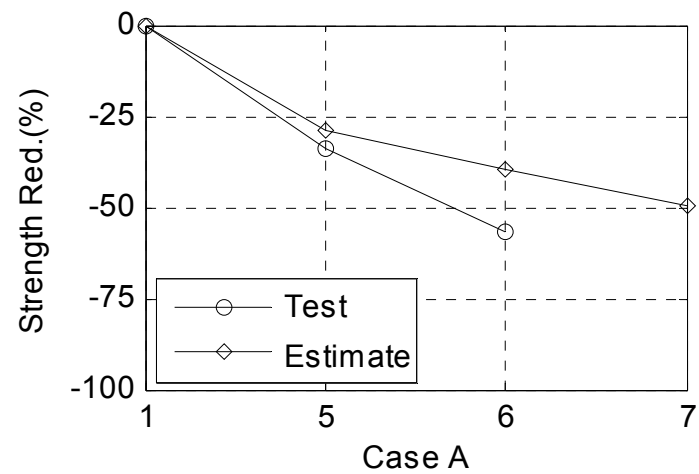

(c)

Figure 9 Model-updating result for specimen without slab: (a) residual stiffness of composite beam; (b) reduction of rotational stiffness; (c) reduction of the strength of the specimen.

\section{CONCLUSIONS}

This paper presented methods for evaluating damage extents and residual capacities for steel beam-column connections using dynamic strain responses under ambient vibrations. In addition, a testing environment to verify the proposed methods was developed. The notable findings are summarized as follows:

(a) The dynamic neutral axis computed by the RMS ratios of dynamic strain responses traced well the shifts of the static neutral axis to the centroid of the steel beam due to the loss of composite action.

(b) The RMS of the dynamic strain responses measured at the bottom flange decreased as fracture increased. For the specimen with floor slab, it was possible to separately examine the influence by the loss of composite action and by beam fracture on these responses. However, further investigations are desirable to identify and remove source of errors.

(c) A model updating strategy using dynamic strain responses succeeded in estimating the residual stiffness and strength of the damaged beam-column connection specimens with reasonable accuracy.

(d) Future studies are needed to quantify the level of uncertainty associated with the proposed strategy. In addition, the influences of multiple damages in dynamic strain distributions should be studied using a multi-span frame model.

\section{ACKNOWLEDGEMENTS}

This work was supported by JSPS KAKENHI Grant Number 26820230, and by the General Collaborative Research program of the Disaster Prevention Research Institute, Kyoto University. 


\section{REFERENCES}

[1] Japan Building Disaster Prevention Association, "The $15^{\text {th }}$ OQ Newsletter: Building Inspection at the Great East Japan Earthquake Disaster and the North Nagano Earthquake" (2013).

[2] Ji, X., Fenves, G. L., Kajiwara, K., and Nakashima, M., "Seismic Damage Detection of a Full-Scale Shaking Table Test Structure" J. Struct. Eng., ASCE, 137(1), 14-21 (2012).

[3] Vanik, M. W., Beck, J. L., and Au, S. K., "Bayesian Probabilistic Approach to Structural Health Monitoring" J. Eng. Mech., 126(7), 738-745 (2000).

[4] Kurata, M., Li, X., Fujita, K., Yamaguchi, M., "Piezoelectric Dynamic Strain Monitoring for Detecting Local Seismic Damage in Steel Buildings" Smart Mat. Struct., 22(11), 115002 (2013).

[5] Li, X., Kurata, M., Nakashima, M., "Evaluating Damage Extent of Fractured Beams in Steel Moment-Resisting Frames Using Dynamic Strain Responses" Earth. Eng. Struct. Dyn., (2014) (posted online ahead of printing).

[6] Sohn, H., and Law, K.H. "A Bayesian Probabilistic Approach for Structure Damage Detection" Earth. Eng. Struct. Dyn., 26(12),1259-1281 (1997).

[7] Dorvash, S., Pakzad, S.N., Labuz, E.L., Ricles, J.M., and Hodgson, I.C., "Localized Damage Detection Algorithm and Implementation on a Large-Scale Steel Beam-to-Column Moment Connection" Earth. Spectra, (2014) (In press).

[8] Yao, G., Chang, K., and Lee, G., "Damage Diagnosis of Steel Frames Using Vibrational Signature Analysis" $J$. Eng. Mech., 118(9), 1949-1961 (1992).

[9] Kurata, M., Minegishi, K., Zyenyun, T. and Nakashima, M., "Change in vibration characteristics of steel beamcolumn connections with composite beams under cyclic loading - vibration tests of full scale specimen-" Journal of Struct. Eng., Architectural of Japan, 703, 1271-1278 (2014) (in Japanese).

[10] Sigurdardottir, D. H., and Glisic, B., "Neutral Axis as Damage Sensitive Feature" Smart Mat. Struct. 22(7), 075030 (2013).

[11] McKenna, F., Fenves, G. L., Scott, M. H., and Jeremic, B., "Open System for Earthquake Engineering Simulation (OpenSees). Pacific Earthquake Engineering Research Center", University of California, Berkeley, $C A,(2000)$.

[12]Mander, J. B., Priestley, M. J. N., and Park, R., "Theoretical Stress-Strain Model for Confined Concrete" J. Struct. Eng., ASCE, 114(8), 1804-1825 (1998).

[13] Horgan, C. O., and Simmonds, J. G., "Saint-Venant End Effects in Composite Structures" Composites Eng., 4, (3), 279-286 (1994).

[14] Sinha, J. K., Friswell, M. I., and Edwards, S. "Simplified Models for the Location of Cracks in Beam Structures Using Measured Vibration Data" J. Sound Vib., 251(1),13-38 (2002). 